\title{
UMA LEITURA GENERIFICADA DA (RE)INAUGURAÇÃO DE UM FAZER PARA MULHERES: DA INGLATERRA AO BRASIL
}

\author{
A GENDER READING ABOUT THE (RE)INAUGURATION OF A FEMALE PRACTICE: \\ FROM ENGLAND TOBRAZIL
}

\author{
UNA LECTURA GENERIFICADA DE LA (RE)INAUGURACIÓN DE UN QUE HACER PARA \\ MUJERES: DESDE INGLATERRA HASTA BRASIL
}

Rosa Maria Godoy Serpa da Fonseca ${ }^{1}$

\begin{abstract}
RESUMO: Trata-se de uma leitura generificada de Florence Nightingale de sua obra principal, "Notas sobre enfermagem: o que é e o que não é", livro que compila os princípios e elementos essenciais da enfermagem moderna, profissionalizada na Inglaterra da segunda metade do século XIX e a maneira como a profissão constituiuse no Brasil, explicitada principalmente na obra de Glete de Alcântara, "A enfermagem moderna como categoria profissional: obstáculos à sua expansão na sociedade brasileira", primeira tese produzida no país, defendida em 1963. Verifica-se que em ambas as situações, que as especificidades da profissão entrecruzam-se com as do mundo do trabalho feminino.
\end{abstract}

PALAVRAS-CHAVE: gênero, enfermagem, história da enfermagem

ABSTRACT: It is a gender reading of Florence Nightingale's main work, "Notes on Nursing: what is and what isn't", a book which brings together the principles and essential elements of modern nursing, professionalized in England in the second half of the XIX century and the way the profession was constituted in Brazil, as explicited in the work of Glete de Alcantara: "Modern nursing as a professional category: obstacles to its expansion in Brazilian society", the first nursing dissertation produced in the country, in 1963.It verified that in both situations the specificities of the nursing profession intermixes with that of the female working world.

KEYWORDS: gender, nursing, history of nursing

RESUMEN: Se trata de una lectura de género de Florence Nightingale de su obra principal " Notas sobre enfermería: lo que es y lo que no es", libro que recoge los principios y elementos esenciales de la enfermeria moderna, cuya profesionalización se dio en Inglaterra en la segunda mitad del siglo XIX y de ahi, como se constituyó la profesión en Brasil, mediante lo expuesto, principalmente, en la obra de Glete de Alcântara, "A enfermagem moderna como categoria profissional: obstáculos a sua expansão na sociedade brasileira". Dicho libro representa la primera tesis sobre el asunto producida en el pais y defendida en 1963. Se verifica que en sendas situaciones las especificidades de la profesión se entrecruzan con las del mundo del trabajo femenino.

PALABRAS CLAVE: género, enfermería, historia de la enfermería

Recebido em 05/08/2001

Aprovado em 06/02/2002

\footnotetext{
${ }^{1}$ Enfermeira. Professora Titular do Departamento de Enfermagem em Saúde Coletiva da Escola de Enfermagem da Universidade de São Paulo.
} 


\section{FLORENCE NIGHTINGALE E "NOTAS SOBRE ENFERMAGEM": CRIADORA E CRIATURA (RE)INAUGURANDO UMA PROFISSÃO E UM FAZER PARA AS MULHERES}

Quase um século e meio depois de sua produção, é instigador analisar o trabalho de Florence Nightingale. Tentar compreendê-lo e a autora significa também tentar compreender as origens da enfermagem moderna como trabalho feminino, cunhado com as mesmas marcas do trabalho de mais da metade da população (a das mulheres), ainda hoje alvo de intensas desigualdades. A questão mote para a presente análise foi: "Qual teria sido a contribuição da fundadora da enfermagem moderna e de suas seguidoras, no que concerne à compreensão da situação social da mulher ?" Uma leitura generificada dessa produção poderia responder a essa indagação.

"Notas sobre enfermagem: o que é e o que não é"

O primeiro parágrafo do livro, de autoria de leda Barreira e Castro, instiga conhecer o seu conteúdo, no que ele revela das idéias da autora sobre as mulheres.

Florence Nightingale (1820-1910), considerada a fundadora da assim chamada enfermagem moderna, tornou-se após quase um século e meio, uma personagem controvertida. As referências feitas à sua pessoa e à sua obra são polarizadas ou pela exaltação de suas excelsas virtudes de criatura predestinada por Deus, que ela mesma se acreditava, ou pela reprovação ao seu apoio à política inglesa, expansionista e dominadora. Uma visão mais justa seria talvez a de uma figura extraordinária, que ousou negar o frustrado destino então reservado às mulheres, mesmo às de sua alta condição social, lançandose a uma vida de ação. Mas que, apesar de haver destoado do seu gênero, foi antes de tudo uma representante de sua época (CASTRO, 1989, p.3).

Florence nasceu e viveu o seu processo de reprodução social no século em que se constatam condições histórico-sociais (Revolução Industrial, avanço no processo de conhecimento, do desenvolvimento das forças produtivas e das relações de produção capitalistas) que permitiram o movimento de resistência ao ambiente sombrio e triste, austero e restritivo para as mulheres, propiciado pela ampla dominação masculina e submissão feminina, construidos anteriormente e que persistiram durante boa parte desse. A partir de 1830, nasce o feminismo, provocando mudanças importantes no mundo das mulheres (trabalho assalariado, autonomia do individuo civil, direito à instrução) e seu aparecimento no cenário político. É o momento histórico em que muda a perspectiva de vida das mulheres, com o surgimento da possibilidade de tornarem-se protagonistas políticas, futuras cidadãs (FRAISSE; PERROT, 1993).

Não se pode dizer que Florence tenha militado em favor dos direitos das mulheres, nem que ela tenha se identificado com o feminismo e seus propósitos, da maneira como o compreendemos na atualidade. Sua meta era tornar a enfermagem um campo de prática feminina reconhecido socialmente, livre dos estereótipos que cercavam as mulheres que cuidavam dos doentes até então. E isso só poderia ter ocorrido em um contexto sócio-político favorável, embora bastante restritivo às mulheres.

Na reconstrução da história das mulheres, para Geneviève Fraisse e Michelle Perrot o século XIX constituiu uma espécie de nexo nessa história, com redistribuição das cartas tradicionais entre o trabalho e a familia, em casa e nos locais de trabalho (fábricas, oficinas, escritórios, etc.).

Ideal de vida doméstico e valor útil para o serviço social, entre o mundo das aparências, o adorno e o prazer, e o mundo da subsistência, a aprendizagem e o exercício de um ofício, entre o lugar da prática religiosa, exercício espiritual e regra social, e o novo espaço da educação, a escola laica. (...) Com maior ou menor ingenuidade ou com maior ou menor consciência, as mulheres rechaçaram a normalização de uma existência que, sem dúvida, se apresentava sob a forma de um ideal; e ainda quando acreditaram nesse ideal, e trataram de aproximar-se dele, também o transformaram (FRAISSE; PERROT, 1993, p.14-15).

Sem abdicar de valores religiosos e humanitários, Florence participou desse movimento. Segundo o biógrafo Woodham-Smith (1951), ela implorava por fazer algo útil ao invés de gastar inutilmente o dinheiro dos pais.

A formidável tarefa realizada por Florence foi a de lograr imiscuir-se no restrito mundo dos negócios públicos do seu poderosíssimo país, influindo em assuntos militares e legislativos. E o fez com grande sucesso: reformou não só os hospitais militares de campanha, mas, também, e de modo considerável, a administração sanitária do exército; participou da elaboração de políticas internas e externas, atuou como expert em assuntos sanitários tornando-se uma autoridade em problemas indianos, e lançou as bases da enfermagem como profissão para todo mundo (CASTRO, 1989, p.3-4).

Corporificando e retransmitindo os valores da sociedade inglesa da época, Florence encarnou a dama burguesa que veio disciplinar a enfermagem na ordem social vigente, militando, a seu modo, pela causa feminista. Sua estratégia foi oferecer às mulheres de então, uma opção ao casamento e à maternidade, negando a compulsoriedade de tais práticas. Fê-lo com as ferramentas que conhecia: disciplinando rigidamente as mulheres no espaço 
público, tanto quanto isso era feito no espaço privado. A Escola funcionou como clausura, mesclando controle da sexualidade e religiosidade com tarefas que, embora historicamente femininas, representavam uma saída para o clássico fazer das mulheres de cuidar. A partir do século XVIII, a Inglaterra passou por um período de reformas, determinado pela Revolução Industrial, que criou uma nova sociedade, com os processos de industrialização e urbanização provocando o aparecimento e a disseminação de doenças. Por outro lado,

A tomada de consciência das condições sanitárias insatisfatórias em que vivia a população fez desencadear uma campanha de saúde pública, considerada por Winslow, como movimento precipuamente social e de caráter humanitário. À reforma das prisões, iniciada por John Howards, seguiu-se a reforma de Lord Shaftesbury, visando a melhoria das condições de trabalho nas fábricas. As modificações da legislação sanitária foram introduzidas após relatório apresentado por Edwin Chadwik à Comissão da Lei dos Pobres. A reforma da enfermagem, iniciada por Florence Nigthingale, em 1860, não foi portanto um fenômeno isolado, porém, parte de um movimento geral para a melhoria das condições da vida humana (ALCÂNTARA, 1963, p.15).

Escolheu fazê-lo, resgatando o valor mais cultivado na Inglaterra Vitoriana - a moral e os bons costumes. Toda a sua obra está impregnada da preocupação em tornar a enfermagem disciplinar, atrativa para moças de boa familia, de classes sociais mais altas que as exercentes da enfermagem tradicional (bêbadas, prostitutas, pobres, "bruxas"). Suas idéias eram contemporâneas à explosão discursiva sobre o sexo, embasada no grande movimento de moralidade, o puritanismo, que começou a transformar a "velha e alegre Inglaterra" em um mundo mais sóbrio e firme. Por decorrência, de uma moralidade aberta, livre e permissiva, passou a ser realidade a demanda por uma constância moral e emocional mais sóbria, em praticamente todas as áreas da vida social (MIRANDA, 1992).

Mandada à Base Militar de Scutari, no Estreito de Bósforo, para reorganizar o Hospital Militar, Florence contratou 38 enfermeiras que assinaram um termo de compromisso submetendo-se inteiramente às suas ordens. Os comportamentos considerados maus na relação com os soldados seriam punidos severamente, com imediata demissão. Jovens mulheres não foram aceitas por representarem tentação ao pecado. A maioria das contratadas era composta de mulheres fortes e mais velhas. Isso porque as enfermeiras não preparadas (mulheres do povo) estavam sempre prontas a beber e causar aborrecimentos, por considerarem que sua função era somente cuidar do corpo dos seus pacientes a seu bel prazer. Já as representantes de ordens religiosas estavam inclinadas a cuidar mais da alma, deixando seus corpos sujos e negligenciados. Algumas enfermeiras recusavam-se a fazer determinados serviços que julgavam degradantes. Por isto, Florence recusou-se a admitir ladies em seu serviço. Todas deveriam ser enfermeiras, comendo o mesmo alimento e usufruindo das mesmas acomodações. Quanto às vestimentas, as freiras e irmãs deveriam usar os seus hábitos e as enfermeiras um uniforme, uma proteção necessária em Scutari, lugar cheio de soldados bêbados e desocupados (WOODHAM-SMITH, 1951).

$\mathrm{Na}$ verdade, Florence estava resgatando as bases dos movimentos anteriores de reforma da enfermagem, tendo por finalidade, uns, a elevação moral e profissional do pessoal hospitalar e, outros, a secularização da profissão. Em 1836, em Kaiserwerth, Alemanha, o pastor luterano Theodor Fliedner e sua mulher Frederika fundaram o Instituto das Diaconisas, visando o renascimento do espírito de serviço das diaconisas dos primeiros tempos da era cristã, muito semelhante à organização das Irmãs de Caridade de São Vicente de Paulo.

Influenciados pelas idéias inovadoras sobre educação, difundidas na Alemanha"nas primeiras décadas do Século XIX, os Fliedners estavam mais preocupados com a formação do caráter de suas alunas do que em ministrar-lhes conhecimentos. Igualmente, a instituição das diaconisas, em seus primeiros tempos, oferecendo oportunidade de trabalho para jovens de classe média, representou um passo à frente para a emancipação da mulher alemã (ALCÂNTARA, 1963, p.14).

Essa instituição influenciou sobremaneira Florence Nightingale, que cumpriu lá o seu primeiro treino fora de um ambiente estritamente hospitalar, periodo considerado por ela como aquele no qual nunca tinha encontrado dedicação mais pura e em seu mais alto grau (WOODHAM-SMITH, 1951).

Como se pode perceber, as bases da reforma da enfermagem assentaram-se sobre o controle da moral, inicialmente das mulheres das classes sociais médias para, anos depois, invadir as classes mais abastadas, quando Florence finalmente aceita admitilas na Escola de Enfermagem de St. Thomas.

"Inicialmente, Florence Nightingale hesitou em receber moças de nivel sócio-econômico elevado, 'as ladies', temendo sua incapacidade para o desempenho do trabalho planejado. Todavia, sua opinião mudou e no relatório da Escola em 1861, escreveu: 'Pessoas de maneiras finas e de educação, 'ladies', de fato, não são, em regra, as que possuem melhores qualidades. Estas são encontradas, em geral, entre mulheres de inteligência acima do normal, provindas de camadas sociais em que as mulheres são 
obrigadas a ganhar a vida. Entretanto, as 'ladies' não devem ser excluídas; pelo contrário, se provarem sua capacidade profissional e tiverem qualidades exigidas para a função de superintendentes, serão admitidas na escola e após o curso poderão, ocupar facilmente, cargos administrativos'. Em outra ocasião, referindose às 'ladies' disse ter sido sua intenção: 'preparar enfermeiras pertencentes a qualquer camada social, a qualquer seita religiosa, habituadas ou não ao trabalho remunerado, contanto que possuissem qualidades morais, intelectuais e físicas para a vocação. Sem dúvida, aquelas que forem educadas, terão mais oportunidades para ocupar cargos de superintendência, não por serem 'ladies', mas por serem educadas. Em 1871, um artigo foi publicado numa revista inglesa sob o titulo: Nursing as a profession for ladies. (ALCÂNTARA, 1963, p.17-18). Ainda com o intuito de redimir a enfermagem, através da formação profissional na Escola de St. Thomas,

A seleção das candidatas, as qualidades morais tinham prioridade; durante o curso, a disciplina era rigorosa. O rigor da escola era justificado, uma vez quie a imoralidade era caráter proverbial da profissão. Qualquer deslize, por pequeno que fosse, qualquer passo em falso, fariam cair a esperança da reforma da enfermagem e a elevação do seu status social seria retardado por muitos anos. O futuro da profissão dependia das alunas, das futuras enfermeiras. (...) o zelo religioso do Instituto das Diaconisas de Kaiserswerth, a disciplina militar dos hospitais de Scutari, o estilo de vida da familia Nightingale, tudo isso foi amalgamado e imposto às primeiras alunas da Escola de St. Thomas. (ALCÂNTARA, 1963, p.17).

É interessante notar que, se de um lado, Florence ousou, a o recusar-se a permanecer no mundo privado, de outro, sua obra mais importante "Notas sobre enfermagem" foi escrita com o propósito de reforçar papéis historicamente femininos, extremamente valorizados no século que constituiu a base histórica para a consolidação do capitalismo, para o qual o trabalho das mulheres, de produção e reprodução da força de trabalho, constituia a base material. No Prefácio, cita que através do livro pretende oferecer sugestões às senhoras que têm a seu cargo pessoal a saúde de outras pessoas, justificando que "todas as mulheres, ou pelo menos quase todas, na Inglaterra, assumem, em algum periodo da vida, a responsabilidade pessoal pela saúde de alguém, criança ou inválido - o que significa que todas exercem a enfermagem" (NIGHTINGALE, 1989, p.11).

Ensina o que considera a base do cuidar através da higienização do ambiente e do próprio paciente, enfatizando a atenção às suas manifestações psico-emocionais.
Assim, ela evidenciou 'o que é e o que não é' enfermagem, mostrando a possibilidade e a necessidade de uma preparação formal e sistemática para a aquisição de um conhecimento de natureza distinta daquele buscado pelos médicos, e cujos fundamentos permitiriam manter o organismo em condições de não adoecer ou de se recuperar das doenças. Sua percepção da doença como um esforço da natureza para restaurar a saúde mostrou-se uma idéia fecunda, dando à enfermagem uma dimensão original, qual seja a de favorecer esse processo reparativo, mediante o uso do ar puro, da luz e do calor, da limpeza, do repouso e da dieta, com um mínimo dispêndio das energias vitais do paciente, de modo a mantê-lo nas melhores condições para que a natureza nele pudesse agir (CASTRO, 1989, p.4-5).

Há que se compreender que o conhecimento epidemiológico da época provocava o debate entre os defensores do paradigma da Teoria Miasmática, dominante e, portanto, defendida pelos conservadores, versus os que atribuiam a doença à pobreza ou a outras condições sociais adversas. Naquele momento, como conseqüência da Revolução Industrial, as cidades cresciam desordenadamente e as condições de vida se agravavam. Os movimentos sociais e revolucionários buscavam soluções para a crise, propiciando o desenvolvimento de estudos sobre as condições de vida da população. Por esta razão, delineavam-se as correntes que iriam subsistir na epidemiologia mais tarde: a miasmática, a microbiana e a social, com a segunda, apesar de incipiente, já identificada e aceita como uma visão moderna da epidemiologia.

Em 1854, Snow publicou estudo sobre a epidemia de cólera intitulado "Sobre a maneira de transmissão do cólera". Pela primeira vez, foi realizada uma pesquisa epidemiológica com o fito de determinar a causa de um surto epidêmico, refutando a teoria miasmática, afirmando a origem hídrica da doença e relacionando-a a "alguma substância que passa do enfermo ao sadio e que tem a propriedade de crescer e se multiplicar no organismo da pessoa" (SNOW, 1991, p. 44). Lançava-se a teoria microbiana.

Foi também a época em que a "patologia social", enquanto corrente de pensamento, fundamentou na França, em 1848, o projeto de intervenção denominado por Guérin, "Medicina Social", designando uma dada concepção de prática médica fundamentada na análise dos problemas sociais e da sua relação com as doenças. Essa corrente era também designada, genericamente, como "modos de tomar coletivamente a questão da saúde" (ALMEIDA FILHO; ROUQUAYROL, 1992, p.16). O foco principal dessa prática eram as medidas para a promoção da saúde e a prevenção das patologias sociais (FONSECA; BERTOLOZZI, 1997). 
O movimento foi iniciado França, por Villermé, que estudou as condições existentes nas fábricas têxteis, demonstrando a relação entre a situação econômica e a mortalidade. Em 1826, sua obra acerca da mortalidade nos diferentes setores de Paris, vinculou a pobreza às doenças. Na Inglaterra, Farr seguiu Villermé, descrevendo a mortalidade em diferentes classes sociais (NAJERA; TERRIS; LOPEZ, 1991)

Estes trabalhos inspiraram-se nas condições criadas pela Revolução Francesa que incorporava, pela primeira vez, os interesses da coletividade na organização social do Estado. Mais que pesquisar as causas das doenças, os revolucionários realizavam uma verdadeira tarefa de saúde pública, trazendo para toda a coletividade, algumas medidas que antes eram privilégio da nobreza (BUCK, 1991). Afinal, não podemos esquecer que o século XIX, nas palavras de Victor Hugo, "tem uma augusta figura materna na Revolução Francesa" que the inspirou todas as artes (HUGO citado por BLOOM, 1996, p.12).

Outro marco importante da época foi a Revolução Industrial, que trouxe em sua economia política a noção de força de trabalho. Necessitando aumentá-la para a sua consolidação através do aumento da industrialização, propiciou a emergência de várias medidas sociais para a sua consecução. Na Inglaterra, por exemplo, a "Nova Lei dos Pobres" rezava que os trabalhadores recebessem assistência médica no local de trabalho e não mais nas paróquias, tentando proteger a força de trabalho do setor produtivo e o exército de reserva em formação (NAJERA; TERRIS; LOPEZ, 1991).

O pensamento dos revolucionários do final do século XVIII e do início do XIX, ligados a diversos movimentos políticos, também apontava para o objeto da ciência médica como sendo o coletivo (concebido sob o recorte da pobreza) e não o individual. Pela primeira vez, a explicação das epidemias adquiria uma dimensão social ligada às condições de vida da população, ampliando a tese da doença como expressão da vida individual sob condições desfavoráveis, no sentido de articulá-la à vida das populações e às deficiências da sociedade. Para Virchow, médico e epidemiologista da época, as condições sociais da pobreza somavam-se às condições atmosféricas, às mudanças cósmicas gerais e coisas parecidas na produção das epidemias e não apenas tais condições ambientais poderiam ser responsabilizadas pelo aparecimento das epidemias (FONSECA; BERTOLOZZI,1997).

Influenciada pelo espírito da época, Florence construiu a enfermagem visando a manutenção de condições ótimas para a recuperação da saúde, enfatizando a atenção individual, embora desde a Criméia tenha baseado suas ações na observação do coletivo, ao estudar as condições em que viviam os soldados feridos que, segundo ela, matavam muito mais que os próprios ferimentos da guerra. Na Criméia, $73 \%$ de 8 regimentos morreram em 6 meses, em conseqüência de doenças (WOODHAM-SMITH, 1951).

Sua visão de saúde-doença e de enfermagem embasava-se numa mescla de várias teorias. Essa foi a razão pela qual algumas das suas Notas foram consideradas ultrapassadas, sem que isso prejudicasse a boa receptividade do livro. Os comentários feitos em Nota do Editor da edição de 1861, revelam o embate vigente na epidemiologia:

Notas sobre Enfermagem (...) foi imediatamente reconhecido pelos lideres da ciência médicosanitária como um trabalho de importância capital, um desses raros livros aos quais, em sua categoria, o termo fazer época pode justificadamente ser aplicado. (...) Aqui e ali um obiter dictum de miss Nightingale foi deixado à margem pela ciência moderna. Devemos ter cuidado em não inferir sobre a crença na geração espontânea da doença ou no seu aparecimento em virtude da 'sujeita' (...) passagens antiquadas como essas não afetam em absoluto o valor dos seus ensinamentos em seu próprio campo. (...) O que continua verdadeiro e atual é a essência do livro - a visão da autora sobre as necessidade de limpeza no ar, na água, nas pessoas, roupas e nos ambientes; de iluminação, silêncio e ordem no quarto do doente; e, na enfermeira, de inteligência, raciocínio, sensibilidade e decência, capacidade de demonstrar real interesse pelo paciente. Isso nunca será ultrapassado (L.H.S.N., 1989, p.157).

O que "nunca será ultrapassado" são as qualidades e a normatização do cuidado através da normatização das atitudes e comportamentos da enfermeira na sua relação com o paciente, sua familia, amigos, médico, etc, idéias que perpassam o livro e que eram de suma importância para Florence Nightingale no seu projeto de reforma da enfermagem. No capitulo "O que significa ser enfermeira" fala sobre os atributos da enfermeira:

Lembre-se: a enfermeira deve ser uma pessoa com a qual se possa contar, isto é, capaz de ser uma enfermeira "digna de confiança". Não sabe quando ela própria está em tal situação; não deve bisbilhotar, nem falar sem necessidade; nunca responder a uma pergunta sobre o paciente exceto àqueles que têm o direito de fazê-la; não há necessidade de dizer que deve ser rigorosamente sóbria e honesta e, mais que isso, uma pessoa religiosa e devotada; deve respeitar sua própria vocação porque a vida, a mais preciosa dádiva de Deus, é posta literalmente em suas mãos; deve ser uma observadora minuciosa, fiel, rápida; uma pessoa de sentimentos delicados e recatados 
(NIGHTINGALE, 1989, 168).

Além de valorizar virtudes e qualidades subjacentes ao puritanismo, a autora valoriza a religiosidade que deve perpassar a prática da enfermagem, revelando um conteúdo ideológico próprio das religiões judaico-cristãs (ela era protestante) para as quais a mulher, ao aproximarse de Deus, o faz em uma situação de subalternidade. O arquétipo religioso da enfermagem seria a mulher divinizada, jamais a Deusa, sempre numa situação subalterna em relação ao Deus único, masculino.

Uma leitura generificada da última parte do livro, quando Florence responde a duas objeções acerca da conveniência das mulheres adquirirem conhecimentos sobre a prevenção de doenças, revela uma postura que pode ser tida como preconceituosa, embora travestida de uma visão transformadora da situação social da mulher, através do exercicio da enfermagem moderna, científica. Refuta a prática amadora e imprudente da medicina por mulheres, alegando que "somente o conhecimento real das normas de saúde pode acabar com isso" (NIGHTINGALE, 1989, p.144). Para ela, no entanto, conhecimento real significa aquele reconhecido cientificamente no campo da medicina, aquele que se contrapõe ao saber popular (empírico) sobre a arte do cuidar, historicamente exercida pelas mulheres. Entre esses conhecimentos não científicos situa inclusive a homeopatia:

A homeopatia introduziu melhora considerável na prática de prescrever remédios por mulheres amadoras, pois suas regras são excelentes, seus remédios praticamente inofensivos - o "glóbulo" é um grão de tolice que parece ser necessário para tornar aceitável qualquer coisa boa. Deixemos então que as mulheres ministrem medicamentos homeopáticos. Se é que têm que administrar algum medicamento, não causarão nenhum mal (NIGHTINGALE, 1989, p.145).

O que ela estava refutando era o conhecimento acumulado durante séculos, que fez das mulheres cuidadoras por excelência, portadoras de um conhecimento que a ciência moderna necessitou expropriar para ganhar espaço e reconhecimento social. Subordinando o conhecimento popular ao científico, Florence objetivava modernizar a enfermagem ainda que subalternizando-a à medicina, rompendo com a tradicionalidade do cuidado feminino. Em várias passagens de seu livro deixa isso claro. Ao referir-se aos laxativos, por exemplo, recomenda às mulheres: "Não tome e não dê a seu filho suas abomináveis 'doses de laxativos' sem o conhecimento do médico" (NIGHTINGALE, 1989). Ou então, justificando o preparo das enfermeiras como uma possibilidade de diminuir os efeitos da automedicação:
$\mathrm{Na}$ verdade isto é exatamente o que uma enfermeira competente e observadora não faz: não se automedica e nem medica outras pessoas. O cultivo dos conhecimentos sobre a observação e a prática da saúde nas mulheres que são mães, governantas ou enfermeiras, é justamente o modo de acabar com os amadores que gostam de receitar. Seria um grande auxilio, ao invés de obstáculo, se os médicos soubessem fazer com que as enfermeiras obedecessem às suas ordens. Esse preparo das mulheres diminuiria o trabalho médico... (NIGHTINGALE, 1989, p.144-145).

Sua atitude é compativel com o que ela acreditava ser o papel das mulheres e dos homens e a hierarquia que deveria se estabelecer entre eles. Para os puritanos, as mulheres eram consideradas inferiores, exceto quanto à alma que era considerada igual à dos homens. No mais, compartilhavam da atitude geral católica, para a qual os homens eram a cabeça, a mulher o corpo, devendo por isto estabelecer-se uma hierarquia inquestionável entre ambos - eles mandavam, elas obedeciam (MIRANDA, 1992).

Uma leitura mais acurada, no entanto, revela que o suporte ideológico em relação ao fazer das mulheres às vezes é dúbio, apesar de à primeira vista pretender-se emancipador da sua situação social. Numa certa passagem, discorrendo sobre a "boa enfermeira", ao mesmo tempo em que revela seu preconceito acerca da luta das mulheres pelos seus direitos, defende que não haja discriminações na divisão sexual do trabalho.

Peço encarecidamente às minhas sisters (irmãs) que fujam de ambos os preconceitos (...); daquele, por exemplo, sobre os "direitos" da mulher que a incentiva a fazer tudo o quanto o homem faz, incluindo a medicina e outras profissões (...); e daquele que incentiva a mulher a não fazer nada do que o homem faz, meramente porque é mulher e deve ser "lembrada do sentido do seu dever como mulher"; e porque "este é um trabalho feminino" e aquele é "um trabalho masculino", e estas 'são coisas que as mulheres não devem fazer', o que nada mais é que pura alegação. (...) O fato de ser extraordinário que uma mulher tenha capacidade de levar a cabo um determinado trabalho, não o faz necessariamente bom. Nem transforma em ruim uma tarefa desempenhada a contento por uma mulher, considerada boa se fosse feita por um homem (NIGHTINGALE, 1989, p.148).

Ainda se posiciona contra a inferioridade social das mulheres quando refuta a idéia de que "para ser uma boa enfermeira nada mais é necessário que um desapontamento amoroso, a falta de objetivo na vida ou a incapacidade para outras atividades". Cita: 
A administração diária de uma grande enfermaria (...) o conhecimento do que significam para os homens as leis da vida e da morte e para as enfermeiras as leis da saúde (...) - esses fatos não constituem, por acaso, questão de importância e dificuldades suficientes para exigir aprendizado, através da prática e de cuidadosa investigação, assim como qualquer outra arte ? Esse conhecimento não chega por inspiração à senhora desiludida e nem ao burro de carga de um asilo de pobres (...). Quantos erros cruéis algumas vezes são praticados por homens e mulheres benevolentes em questões sobre as quais nada sabem e pensam que sabem muito (NIGHTINGALE, 1989, p.147).

Em sintese, essa análise e muitas outras que comportam a personagem mostram uma mulher com conhecimentos e práticas contraditórios, filha de uma época cuja marca principal foi essa contradição: ao mesmo tempo que impele as mulheres para uma vida subalternizada, secundária, ilumina caminhos para a superação dos seus papéis sociais tradicionais. Florence compreende a enfermagem como um campo de prática feminino, que deve ser exercida sob os auspicios da medicina, com base científica, um cenário excelente para um fazer das mulheres reconhecido socialmente. Acima de tudo, constitui uma possibilidade para o rompimento de estereótipos através do resgate do seu conteúdo moral e de bons costumes.

Assentada nesses mesmos pilares, essa enfermagem primeiromundista migrou para a América Latina e para o Brasil, desafiando o cuidar assistemático, acientífico, exercido por sujeitos sociais igualmente alvos de preconceitos e estereotipias, dentre eles, mulheres pobres e de "conduta moral suspeita". Uma das melhores descrições dessa situação e da maneira como ela foi enfrentada é feita por Glete de Alcântara, na primeira tese de enfermagem brasileira, defendida em 1963, na Escola de Enfermagem de Ribeirão Preto, intitulada

A enfermagem moderna como categoria profissional: obstáculos à sua expansão na sociedade brasileira". Seus objetivos consistiram em: "a) analisar as condições em que emergiu a enfermagem moderna na sociedade brasileira e os fatores que têm interferido negativamente no seu desenvolvimento; b) averiguar se a posição atribuida à enfermeira diplomada, na hierarquia de prestígio ocupacional, em Ribeirão Preto, evidencia mudanças que ocorrem no sentido de reduzir os obstáculos à maior expansão dessa categoria profissional. (ALCÂNTARA, 1963, p.4)

$A$ análise é feita tendo como referência a situação histórico-social em que a prática de enfermagem foi institucionalizada no pais, comparada ao desenvolvimento sócio-econômico e cultural da Inglaterra e dos Estados Unidos, respectivamente, pais de origem da enfermagem moderna e, o outro, aquele através do qual o conhecimento de enfermagem migrou para o Brasil. Além disso, embora não admitido claramente pela autora, permeia toda a análise a situação peculiar das mulheres como estrato social privilegiado em termos de subalternização. Essa é a razão pela qual essa pesquisa pode ser considerada também o primeiro estudo de gênero acerca do trabalho da enfermagem no nosso pais, muito à frente do seu tempo em termos de construção do saber.

\section{A CONSTRUÇÃO DA ENFERMAGEM NO BRASIL: OS FUNDAMENTOS DE UMA PROFISSÃO FEMININA}

Até o século XIX e inicio do XX, a enfermagem tradicional no Brasil seguiu os termos da enfermagem pré-moderna européia, tendo como seus principais exercentes pessoas não preparadas especificamente para o cuidado aos doentes. A finalidade desse trabalho era caritativa, desvinculada de qualquer pretensão de cura, mesmo após a institucionalização do trabalho médico. O próprio Relatório da Comissão especial incumbida de elaborar o Ante-Projeto de Lei Orgânica de Assistência Médico-Hospitalar, ao referirse ao nivel de eficiência do pessoal hospitalar, o fez nos seguintes termos:

Os médicos, grupo qualificado, geralmente contam com auxiliares de baixo padrão, exdoentes, sem preparação alguma, individuos que comumente não têm capacidade sequer para os trabalhos domésticos. Há felizmente exceções. Nestas estão incluidas as Irmãs de Caridade, que procuram muitas vezes suprir, com desvelo e dedicação, a falta de preparo na arte da enfermagem ou na administração (ALCÂNTARA, 1963, p.11).

Quanto à proximidade do trabalho da enfermagem de então com o trabalho doméstico, Glete de Alcântara afirma:

A conhecida praxe, adotada principalmente pelas Santas Casas, de empregar, no setor de enfermagem, antigos pacientes e de promover como 'enfermeiros' as pessoas admitidas para o serviço de limpeza que demonstrassem habilidade no cuidado aos doentes explicava, de certo modo, as razões da identificação de atividades hospitalares com o tipo de trabalho manual, desempenhado por empregados domésticos (ALCÂNTARA, 1963, p.43).

No intuito de romper essa situação, o ensino da enfermagem foi instituido oficialmente no Brasil, em 1890, com a criação da Escola Profissional de Enfermeiros e Enfermeiras no Governo provisório da Segunda República. Sob a direção e com um corpo docente composto somente por médicos, tinha como 
destinação especifica formar pessoal para trabalhar junto ao Hospital Nacional de Alienados. Não pretendia instituir-se senão para isso, não visando transformar qualitativamente a assistência, senão que obter tal transformação intervindo diretamente no preparo dos exercentes da enfermagem.

O curso, de dois anos, exigia para a matricula que o candidato soubesse 'ler e escrever corretamente e conhecer aritmética elementar'. (...) Considerando-se que somente a partir do início do século, a educação primária começou a difundir-se e que a taxa de analfabetismo da cidade do Rio de Janeiro, em 1900 era de 37\% entre pessoas maiores de 15 anos, não seria exagero afirmar ser o curso anexo simplesmente de alfabetização. (...) As condições da sociedade brasileira, no começo do século, impediram a organização de uma escola conforme o sistema Nightingale e aqueles médicos admiráveis tiveram que se contentar com o tipo de instituição educacional que precisava, antes de mais nada, alfabetizar seus futuros alunos (ALCÂNTARA, 1963, p.12).

Depois desta, foi criada outra Escola nas mesmas condições, junto ao Hospital Evangélico, hoje Hospital Samaritano, conduzida exclusivamente por enfermeiras inglesas e com a mesma finalidade de formar pessoal para o próprio Hospital. Dadas as peculiaridades dessas escolas, principalmente no que se referia à sua restrição em formar pessoal destinado para lotar os quadros dos hospitais a que se vinculavam, o início da enfermagem moderna brasileira, formando profissionais para trabalhar em todo o território nacional, pode ser atribuido à criação da Escola de Enfermeiras do Departamento Nacional de Saúde, hoje Escola Ana Néri, em 1923, no Rio de Janeiro. Contrariamente às anteriores, foi fundada sob a égide da saúde pública, subordinada ao Departamento Nacional de Saúde Pública, embora anexa ao Hospital Geral da Assistência daquele Departamento (ANGERAMI, 1985).

A sua criação foi determinada pela necessidade de preparar recursos humanos para favorecer a melhoria das condições de saúde da população, com o objetivo de protegê-la das epidemias e endemias que colocavam em risco a mão de obra nacional ou imigrante, vinculada ao setor agrário-exportadorcafeeiro, predominante na época. Além disso, havia a necessidade de assegurar a manutenção das relações comerciais entre o Brasil e as potências estrangeiras, ameaçadas de serem suspensas por estas, caso os portos não fossem saneados. O próprio curriculo vigente destacava o predominio de disciplinas preventivas compativel com os objetivos da escola (GERMANO, 1988).

A fundação da Escola de Enfermeiras do Departamento Nacional de Saúde Pública, constituiu o marco inicial da enfermagem moderna no pais, e resultou da organização das forças sociais inovadoras no campo da saúde pública. Com a reorganização do Departamento Nacional de Saúde Pública, em 1920, verificouse a necessidade de pessoas especializadas que continuassem a desempenhar, junto às familias, o trabalho de educação sanitária iniciado pelos médicos nos novos ambulatórios. Carlos Chagas, diretor do Departamento, conhecendo a organização de tais serviços nos Estados Unidos, solicitou a cooperação da Fundação Rockefeller para solucionar o problema. Como resultado dos entendimentos, chegou à cidade do Rio de Janeiro, em 1921, Ethel Parsons, enfermeira norte-americana, com o objetivo de estudar a situação local e elaborar um projeto para a ação. No plano apresentado (...) estava contida a criação de uma escola de enfermagem para formação de pessoal de elevado nivel técnico.(...) em 1923, foi instalada no ex-Distrito Federal, a Escola de Enfermeiras do Departamento Nacional de Saúde Pública. Sob a orientação de Ethel Parsons, esse novo estabelecimento foi organizado segundo as mais modernas tendências de educação de enfermagem nos Estados Unidos (ALCÂNTARA, 1963, p.13).

À semelhança do que Florence Nightingale havia feito na Inglaterra, a enfermagem, no Brasil, desde seus primórdios, no início dos anos 20 , também objetivava constituir uma opção alternativa de trabalho feminino "para jovens da nova classe média, em contínuo crescimento que até então encontravam no magistério primário as únicas oportunidades para atividades remuneradas" (ALCÂNTARA, 1963, p.21). Calcada nos mesmos pressupostos androcêntricos verificados nas sociedades inglesa e americana, aqui também a enfermagem seria alvo dos mesmos estereótipos, razão pela qual foi pensada até a adoção de um novo nome para a profissão:

Conhecendo a conotação negativa da palavra "enfermeira" para a sociedade brasileira da época (...), Ethel Parsons hesitou em adotá-la para o novo tipo de profissional. Nos arquivos da Escola Ana Néri (...) foram encontradas folhas (...) com o seguinte cabeçalho: 'Inscrição para a Escola Preparatória de Nurses de São Francisco de Assis'. A palavra "nurse" foi contudo rejeitada, prevalecendo o termo enfermeira ao qual acrescentava-se verbalmente a expressão "altopadrão" ou "de saúde pública" ou simplesmente "diplomada" para indicar a nova categoria (ALCÂNTARA, 1963, p.24)

$A$ aceitação da nova profissão era igualmente problemática dadas as condições sociais do pais que não comportavam o desenvolvimento de uma profissão feminina de nivel universitário, mesmo calcada em padrões educacionais considerados avançados como os americanos. No Distrito Federal, por exemplo, havia 
aproximadamente um quarto de analfabetos entre as pessoas adultas, dentre as quais, era maior o percentual de representantes do sexo feminino, em especial das classes menos favorecidas. A educação das mulheres de niveis sócio-econômico mais altos limitava-se aos programas ministrados por religiosas, em colégios femininos, que não se enquadravam no sistema educacional do pais. A única carreira para jovens de boa familia, que precisavam ganhar a vida era o magistério. Tais condições, apesar de altamente desfavoráveis eram pouco questionadas mesmo porque, coletivamente o movimento de emancipação feminina era apenas um esboço. (ALCÂNTARA, 1963)

Quanto à semelhança entre os contextos sócioculturais brasileiro e inglês da não aceitação da profissão, cita:

Comparando-se a sociedade brasileira no início da década dos vinte com a inglesa e norteamericana, na segunda metade do século XIX, época em que foi introduzida a escola Nightingale, havia um aspecto comum a ambas: o conceito desfavorável atribuido à enfermagem como ocupação. Ao passo que na Inglaterra e nos Estados Unidos o desenvolvimento da urbanização-industrialização propiciou a expansão das escolas de enfermagem, o Brasil, na década dos vinte não estava (...) preparado para favorecer o incremento da nova profissão. (ALCÂNTARA, 1963, p.26)

Ainda que persistindo na década de 60, o registro das concepções negativas acerca da enfermagem encontrava-se presente desde o inicio da formação profissional da enfermagem:

A primeira turma de diplomadas pela Escola Ana Néri estava consciente da existência de concepções negativas acerca do exercício da enfermagem, como indica uma passagem do pequeno livro 'As Pioneiras', publicado na ocasião da sua formatura, em 1925. Nessa publicação, foram feitas referências à diretora norteamericana da Escola nos seguintes termos: 'Miss Louise Kienninger, abandonando a pátria distante, veio doar ao nosso País, o maior serviço social moderno, abolindo o preconceito de não se poder ser enfermeira sem corar. Ao espírito da ilustre educadora devem as brasileiras, que ontem teriam pejo de ser enfermeiras, o poder hoje se enobrecerem e se orgulharem desse título (ALCÂNTARA, 1963, 1963, 37).

No livro citado anteriormente, "As Pioneiras", também encontram-se os fundamentos da obediência que as enfermeiras deviam aos médicos, no cuidado aos doentes, outro expressivo pilar sobre o qual foi construida a enfermagem brasileira, baseado na relação entre os sexos e entre saberes, hegemonicamente masculino e médico. Segundo Sobral (1994), o jogo de palavras da apresentação implica num entendimento sublime, bem perto do mágico ou do divino, que vai construindo a imagem pública da mulher enfermeira. Tal mulher que, até então, tinha na função de mãe-esposa-dona de casa sua contribuição social máxima sob a tutela do marido, vai ser transportada para a tutela do médico, figura máxima de poder no hospital. Sempre sob as ordens do médico, a enfermeira deve fazer aquilo que ele não faz, porém sob suas ordens. Identifica-se ai o inicio das interdições sociais onde se isola o aspecto mais privado para que o aspecto público da performance feminina possa acontecer. (SOBRAL, 1994).

Ainda em 1963, a tese de Glete de Alcântara revela a existência de preconceito e discriminação negativa em relação à profissão de enfermagem. Segundo ela, no conteúdo das opiniões e atitudes dos pais que se opõem à matricula das filhas no curso de enfermagem verifica-se a relação dessa profissão com atributos intelectuais e morais considerados socialmente inferiores, manifestados pela sua conotação de 'profissão mal vista'. Tais atributos indicam a preservação de padrões historicamente herdados, relativos às atividades manuais da enfermagem (ALCÂNTARA, 1963).

Em sintese, o inicio da enfermagem como ciência, buscando desenvolver um corpo de conhecimentos próprios, começou a manifestar-se algum tempo depois. Anteriormente, a prática "era fundamentada em normas e tradições e norteava-se por principios e proposições extraidos das ciências físicas e biológicas que lhe conferiam um caráter científico, principal e preponderantemente em relação às técnicas. A partir dai, novas forças foram empreendidas na busca de um conteúdo cognitivo próprio, na formulação de alguns conceitos, bem como no aperfeiçoamento de enunciados existentes." (...) Mais tarde, entre 60 e 70 "se intensifica a preocupação com o aspecto epistemológico da enfermagem, preocupações estas traduzidas pela ordenação sistemática do seu corpo de conhecimentos e teorias" (TREVISAN; MENDES; ANGERAMI, 1992, p.91).

\section{A REINVENÇÃO DO CAMINHO: RUMO À ENFERMAGEM GENERIFICADA}

Os pilares sobre os quais foi construida a enfermagem moderna e a forma como foram incorporados na sociedade brasileira revelam contradições inerentes à visão de mulher à época da sua construção e, de lá para cá, têm sido ao mesmo tempo reiterados e contestados, pendularmente. No que tange à construção da identidade da mulherenfermeira ora favorecem, ora dificultam a assunção de posturas transformadoras.

Tal legado, acrescido das mudanças sociais que propiciaram a emergência das questões das mulheres como pauta social, levou à necessidade dos 
estudos de gênero para melhor compreender a enfermagem como profissão feminina e as enfermeiras como trabalhadoras, em pé de igualdade em relação às demais mulheres, integrantes de outros fazeres profissionais. Assim é que têm crescido em quantidade e em qualidade as investigações dessa natureza e, graças a elas, na atualidade podemos compreender melhor a realidade e vislumbrar caminhos para a superação da subalternidade que nos caracteriza enquanto saber e enquanto prática, no conjunto de saberes e práticas da área da saúde.

A análise generificada do principal trabalho de Florence Nightingale tida, durante muito tempo, como reiteradora da tal condição de subalternidade, mostrou que ela foi pioneira ao advogar a visibilidade e a valorização social do trabalho da enfermeira. Se até hoje pagamos o ônus de termos nascido sob a égide da ideologia androcêntrica do puritanismo e se, por conta disso, foi transmitido como verdade a imagem da enfermeira servil e subalterna ao médico, em oposição, a modernidade lançou as sementes de uma nova enfermagem como profissão independente, autônoma e aliada às demais práticas sociais, num contexto que não comporta deusas, anjos ou bruxas, mas mulheres trabalhadoras que, aliadas aos demais trabalhadores, batalham para um mundo melhor.

Para isso, cabe a nós, enfermeiras da atualidade e suas sucessoras, reinventar o caminho iniciado, construindo também o que será deixado a quem se dispuser a nos suceder, na continua (re)inauguração de uma profissão e um fazer para as mulheres que encerram possibilidades impares de transformação pessoal e coletiva.

\section{REFERÊNCIAS BIBLIOGRÁFICAS}

ALCÂNTARA G. A enfermagem moderna como categoria profissional: obstáculos à sua expansão na sociedade brasileira. Ribeirão Preto, 1963. Tese (Cátedra) - Escola de Enfermagem de Ribeirão Preto/USP.

ALMEIDA FILHO N. Epidemiologia sem números: uma introdução critica à ciência epidemiológica. Rio de Janeiro(RJ): Campus, 1989

ALMEIDA FILHO, N.; ROUQUAYROL, M.Z. Introdução à Epidemiologia Moderna. 2. ed. Salvador(BA)/Rio de Janeiro(RJ): APCE/ABRASCO, 1992.

BLOOM, H. A grandiosidade de um poeta épico sem precursores. Folha de São Paulo, 7 de julho de 1996. Caderno Mais, p.12.
BUCK, C. et al. El desafio de la epidemiologia: problemas y lecturas selecionadas. 2. ed. Washington: OPAS/OMS, 1991. (Publicación Científica $n^{\circ}$ 505). 1077 p.

CASTRO, I.B. Prefácio à edição brasileira. In: NIGHTINGALE, F. Notas sobre enfermagem: o que é e o que não é. São Paulo: ABEn/CEPEN, 1989. p.3-10.

FONSECA, R.M.G.S.; BERTOLOZZI, M.R. A epidemiologia social e a assistência à saúde da população. In: Associação Brasileira de Enfermagem. A classificação das práticas de enfermagem e o uso da epidemiologia social. Brasília: Associação Brasileira de Enfermagem, 1997. (Série didática: Enfermagem no SUS), p. 1-59.

FRAISSE; G. ; PERROT, M. Introducción. In: DUBY, G.; PERROT, M. Historia de las mujeres en occidente. Madrid: Taurus, 1993. Tomo 7: EI siglo XIX - la ruptura politica y los nuevos modelos sociales, bajo la dirección de Geneviève Fraisse y Michelle Perrot.

GERMANO, R.M. Educação e ideologia da enfermagem no Brasil. 2. ed. São Paulo: Cortez, 1988.

L.H.S.N. Notas do editor. In: NIGHTINGALE, F. Notas sobre enfermagem: o que é e o que não é. São Paulo: ABEn / CEPEN, 1989. p.156-8.

MIRANDA, C.M.L. O discurso da sexualidade como eixo de instrução da Enfermagem Moderna. Saúde em Debate, Londrina, n.36, p. 73-5, 1992.

NAJERA, E.; TERRIS, M.; LOPEZ, A. Discusión. In: BUCK, C. et al. El desafio de la epidemiologia: problemas y lecturas selecionadas. 2. ed. Washington: OPAS/OMS, 1991. (Publicación Científica $n^{\circ} 505$ ) p. 3-17, p. 1055-73.

NIGHTINGALE, F. Notas sobre enfermagem: o que é e o que não é. São Paulo: ABEn / CEPEN, 1989.

SNOW, J. Sobre el modo de transmisión del cólera. In: Buck, C. et al. El desafio de la epidemiologia: problemas y lecturas selecionadas. 2. ed. Washington: OPAS/OMS, 1991. (Publicación Científica $\left.n^{\circ} 505\right)$ p. 43-6.

SOBRAL, V.R.S. Construindo uma profissão feminina. Rev. Enferm. UERJ, v.2, n.2, p.242-9, 1994.

TREVISAN, M.A.; MENDES, I.A.C.; ANGERAMI, E.L.S. A investigação em enfermagem no Brasil. Rev. Paul. Enf., São Paulo, v. 10, n.3, p.91-5, 1992.

WOODHAM-SMITH, C. Florence Nightingale. New York: McGraw-Hill Book Co, 1951. 